\title{
REFERENCES
}

1. R. H. Cameron, A "Simpson's Rule" for the numerical evaluation of Wiener's integrals in function space, Duke Math. J. 18 (1951), 111-130.

2. Henry C. Finlayson, New approximations for Wiener integrals, with error estimates, Canad. J. Math. 19 (1967), 58-105.

3. E. L. Ince, Ordinary differential equations, Dover, New York, 1956.

UNIVERSITY OF MANITOBA

\section{REMARKS ON SOME CONVERGENCE CONDITIONS FOR CONTINUED FRACTIONS}

DAVID F. DAWSON

In [4] Farinha proved the following theorem concerning the continued fraction

$$
\frac{1}{1}+\frac{a_{1}}{1}+\frac{a_{2}}{1}+\frac{a_{3}}{1}+\cdots .
$$

TheOREm. Suppose the $a_{k}$ are functions of a complex variable defined in a region $D$. If the $a_{k}$ satisfy at each point of $D$ the conditions

(i) no term of $\left\{a_{n}\right\}$ is zero, but $\lim _{n} a_{n}=0$,

(ii) $\left|a_{1}\right| \leqq \alpha$ and $\left|1+a_{1}\right| \geqq\left|a_{1}\right|+\mu$, where $\alpha$ and $\mu$ are positive constants, and

(iii) $\left|1+a_{n}+a_{n+1}\right| \geqq 2\left|a_{i}\right|, i=n, n+1 ; n=1,2,3, \cdots$, then the continued fraction (1) converges uniformly over $D$ and the modulus of its value does not exceed the smaller of the numbers $3 / 2$ and $(\alpha+\mu) / \mu^{2}$.

Convergence of (1) under Farinha's three conditions follows from a theorem of Scott and Wall [6, Theorem 3.4].

In this note we show that (iii) alone is sufficient to give convergence of the continued fraction (Theorem 1), and, using the basic idea involved in the proof, we extend a theorem of the author $[3$, Theorem A].

THEOREM 1. If for each positive integer $n,\left|1+a_{n}+a_{n+1}\right| \geqq 2\left|a_{i}\right|$, $i=n, n+1$, then the continued fraction (1) converges.

Proof. From the hypothesis and the triangle inequality we can

Presented to the Society, April 22, 1966; received by the editors May 14, 1966. 
easily show that the inequalities of Scott and Wall $[3$, p. 698] hold for $r_{p}=1, p=1,2,3, \cdots$, with actual inequality in the second of the first two relations. If some $a_{p}=0$, then by Theorem A of [6] the continued fraction (1) converges. Suppose no $a_{p}=0$. Let $b_{1}=1, b_{p+1}$ $=1 / a_{p} b_{p}, p=1,2,3, \cdots$. If $n$ is a positive integer, then

$$
\begin{aligned}
\left|1+a_{2 n}+a_{2 n+1}\right| & \geqq 2\left|a_{2 n+1}\right|, \\
\left|1+1 / b_{2 n} b_{2 n+1}+1 / b_{2 n+1} b_{2 n+2}\right| & \geqq 2 /\left|b_{2 n+1} b_{2 n+2}\right|,
\end{aligned}
$$

and so, using the triangle inequality, we obtain

$$
\left|b_{2 n+1}\right| \geqq 1 /\left|b_{2 n+2}\right|-1 /\left|b_{2 n}\right| \text {. }
$$

Thus if $k$ is a positive integer, then

$$
\sum_{p=1}^{k}\left|b_{2 p+1}\right| \geqq 1 /\left|b_{2 k+2}\right|-1 /\left|b_{2}\right|,
$$

and from this inequality we see that if $\sum\left|b_{2 p}\right|<\infty$, then $\sum\left|b_{2 p+1}\right|$ $=\infty$. Hence $\sum\left|b_{p}\right|=\infty$, and so by Corollary $3.3 \mathrm{~b}$ of [1] the continued fraction (1) is convergent.

The next theorem extends a result of the author [3, Theorem A]. A similar result is obtained if the roles of even and odd indices are in terchanged.

THEOREM 2. If $\left\{a_{p}\right\}$ is a complex sequence and $\left\{r_{p}\right\}$ is a sequence of nonnegative numbers such that

$$
\begin{aligned}
r_{1}\left|1+a_{1}\right| & \geqq\left|a_{1}\right|, \quad r_{2}\left|1+a_{1}+a_{2}\right| \geqq\left|a_{2}\right|, \\
r_{p}\left|1+a_{p-1}+a_{p}\right| & \geqq r_{p} r_{p-2}\left|a_{p-1}\right|+\left|a_{p}\right|, \quad p=3,4,5, \cdots,
\end{aligned}
$$

$Q=\left\{t: r_{2 t} \leqq 1\right\}$ is an infinite set, and $\sum\left|1-r_{2 p}\right|=\infty$, then the continued fraction (1) converges at least in the wider sense, and if actual inequality holds in either of the first two relations of (2), then (1) converges.

Proof. If some $a_{q}=0$, then (1) converges [6, Theorem A]. Suppose no $a_{q}=0$, and let $b_{1}=1, b_{p+1}=1 / a_{p} b_{p}, p=1,2,3, \cdots$. We will now show that $\sum\left|b_{p}\right|=\infty$. Note that $r_{p}>0, p=1,2,3, \cdots$. If $p$ is an integer greater than 1 , then

$$
\begin{gathered}
r_{2 p}\left|1+a_{2 p-1}+a_{2 p}\right| \geqq r_{2 p} r_{2 p-2}\left|a_{2 p-1}\right|+\left|a_{2 p}\right|, \\
r_{2 p}\left|1+1 / b_{2 p-1} b_{2 p}+1 / b_{2 p} b_{2 p+1}\right| \geqq r_{2 p} r_{2 p-2} /\left|b_{2 p-1} b_{2 p}\right|+1 /\left|b_{2 p} b_{2 p+1}\right|,
\end{gathered}
$$

and so, using the triangle inequality, we obtain

$$
\left|b_{2 p}\right| \geqq\left(1 / r_{2 p}-1\right) /\left|b_{2 p+1}\right|-\left(1-r_{2 p-2}\right) /\left|b_{2 p-1}\right| \text {. }
$$


Thus if $n$ is an integer greater than 1 and $n+j \in Q$, then from (3) we have

$$
\sum_{i=n}^{n+j}\left|b_{2 i}\right| \geqq \sum_{i=n}^{n+j-1} \frac{\left(1-r_{2 i}\right)^{2}}{r_{2 i}\left|b_{2 i+1}\right|}-\frac{1-r_{2 n-2}}{\left|b_{2 n-1}\right|}
$$

Suppose $\sum\left|b_{2 p+1}\right|<\infty$. We will consider two cases. First suppose $\left\{r_{2 p}\right\}$ is bounded. Let $A=\left\{t:\left|1-r_{2 t}\right|>\left|b_{2 t+1}\right|\right\}$ and $B=\left\{t:\left|1-r_{2 t}\right|\right.$ $\left.\leqq\left|b_{2 t+1}\right|\right\}$. Since $\sum\left|b_{2 p+1}\right|<\infty$, then $\sum_{p \in B}\left|1-r_{2 p}\right|<\infty$. Thus $\sum_{p \in A}\left|1-r_{2 p}\right|=\infty$ since $\sum\left|1-r_{2 p}\right|=\infty$. Hence

$$
\sum_{p \in A} \frac{\left|1-r_{2 p}\right|}{\left|b_{2 p+1}\right|}\left|1-r_{2 p}\right|=\infty,
$$

and so from (4) we see that $\sum\left|b_{2 p}\right|=\infty$ since $\left\{r_{2 p}\right\}$ is bounded. Next suppose $\left\{r_{2 p}\right\}$ is unbounded. Let $C=\left\{t: r_{2 t}>2\right\}$. Clearly

$$
\sum_{p \in C} \frac{1-1 / r_{2 p}}{\left|b_{2 p+1}\right|}\left(r_{2 p}-1\right)=\infty
$$

since $\sum\left|b_{2 p+1}\right|<\infty$. Hence from (4), $\sum\left|b_{2 p}\right|=\infty$. Thus we have shown that if $\sum\left|b_{2 p+1}\right|<\infty$, then $\sum\left|b_{2 p}\right|=\infty$. Consequently $\sum\left|b_{p}\right|=\infty$. Thus by Theorem 3.3 of [1] and Theorem A of [2] the continued fraction (1) converges at least in the wider sense since the even and odd parts of (1) both converge absolutely at least in the wider sense, and if actual inequality holds in either of the first two relations of (2), then by Corollary $3.3 \mathrm{~b}$ of [1] the continued fraction (1) converges. Hence the theorem is proved.

It is easy to show that the part of the hypothesis requiring $Q$ to be an infinite set cannot be omitted. Let $r_{p}=2$ and let $a_{p}=2^{p}$, $p=1,2,3, \cdots$. Clearly the inequalities (2) are satisfied. Divergence of (1) follows from a theorem of Leighton [5, Theorem 1].

\section{REFERENCES}

1. D. F. Dawson, Concerning convergence of continued fractions, Proc. Amer. Math. Soc. 11 (1960), 640-647.

2. - Convergence of continued fractions of Stieltjes type, Proc. Amer. Math. Soc. 10 (1959), 12-17.

3. - A theorem on continued fractions and the fundamental inequalities, Proc. Amer. Math. Soc. 13 (1962), 698-701.

4. João Farinha, Sur la convergence de $\phi a_{i} / 1$, Portugal. Math. 13 (1954), 145-148.

5. Walter Leighton, A test-ratio test for continued fractions, Bull. Amer. Math. Soc. 45 (1939), 97-100.

6. W. T. Scott and H. S. Wall, A convergence theorem for continued fractions, Trans. Amer. Math. Soc. 47 (1940), 155-172.

North TeXas State University 